\title{
Development of a radiative heating system for studies of heat transfer in fuel-cooled structures
}

\author{
Da Dong ${ }^{1}$, Yang Lu², Yueming Yuan ${ }^{3}$, Xuejun Fan ${ }^{4}$ \\ LHD, Institute of Mechanics, Chinese Academy of Sciences, Beijing, 100190, P. R. China
}

\begin{abstract}
A radiative heating system was designed to simulate the heat exchange between the hot gas and the fuel-cooled structure in a scramjet combustor. A flat-plate cooling structure was heated unilaterally using thermal radiation from an electrically-heated graphite plate. The system was designed to work at a maximum heat flux of $1.5 \mathrm{MW} / \mathrm{M}^{2}$ for the effective heating area up to $1000 \mathrm{~mm} \times 40 \mathrm{~mm}$.
\end{abstract}

\section{Introduction}

Regenerative cooling has been considered to be an effective thermal-management method for hydrocarbonfueled scramjets ${ }^{[1][2]}$. There are two simultaneous processes in a regenerative-cooling combustor. Coolant fuel is flowing through micro channels embedded in the combustor wall to cool down the combustor. Meanwhile, the heated fuel is injected to the combustion chamber to burn and gain thrust. As a result, high heat flux is produced toward the combustor wall. The average heat flux in a typical scramjet combustion chamber reaches $1.0 \mathrm{MW} / \mathrm{m}^{2}{ }^{[3]}$. Hydrocarbon coolant may become supercritical or partially cracked under such typically working conditions. The heat transfer and flow characteristics are quite complicated due to the rapid changes in fuel states and their thermophysical properties during the cooling process. Many studies on this problem have been performed. $\operatorname{Fan}^{[4][5]}$ investigated the thermophysical properties and heat transfer characteristics of aviation kerosene under supercritical conditions experimentally and analytically. Qin-Cheng $\mathrm{Bi}^{[6]}$, J. Giovanetti ${ }^{[7]}$ and D. L. Linne ${ }^{[8]}$ experimentally investigated the convective heat transfer characteristics of supercritical-condition hydrocarbon fuel in an electrically heated tube respectively. Hong-Wu Deng ${ }^{[9]}$ investigated the flow frictional resistance characteristics of kerosene RP-3 in horizontal circular tube at supercritical pressure with an experimental method. Besides, there are also some numerical investigations on this problem. The result of Zhong ${ }^{[10]}$ 's study shows that the large change of the thermophysical properties of the aviation kerosene at the supercritical pressure complicates the heat transfer in tubes.

Nonetheless, heat transfer in an electric-heated tube, which is widely used to simulate regenerated-cooled conditions in abovementioned literature, is different from that in the structure of a combustor wall. Firstly, joule heat is produced by current in the whole electrified area of the tube while in the combustor wall, however, heat flow is transferred through the surface. The former is inherently a body-heating condition but for the combustor wall, sideheating is dominating. Secondly, heat transfer in long narrow electric-heated tubes can hardly represent the two-fold problem of the heat conduction within cooling structure with channels embedded and the convective heat transfer of coolant flowing through them. Mutually influences of these two processes are often missing in electric-heated tube studies. The heat transfer problem here should be treated as "conjugate heat transfer" [11], with the heat flux resulting from combustion and aerodynamic heating process be taken as a boundary condition, which is illustrated in figure.1. Hence a one side high-flux heating device is requisite for experimental simulation or recurrence of conjugate heat transfer in a regenerative-cooling combustor.

\footnotetext{
${ }^{1}$ PhD student, dongda12@mails.ucas.ac.cn

${ }^{2}$ Assistant Professor

${ }^{3}$ Assistant Professor

${ }^{4}$ Professor, xfan@imech.ac.cn, Member AIAA
} 


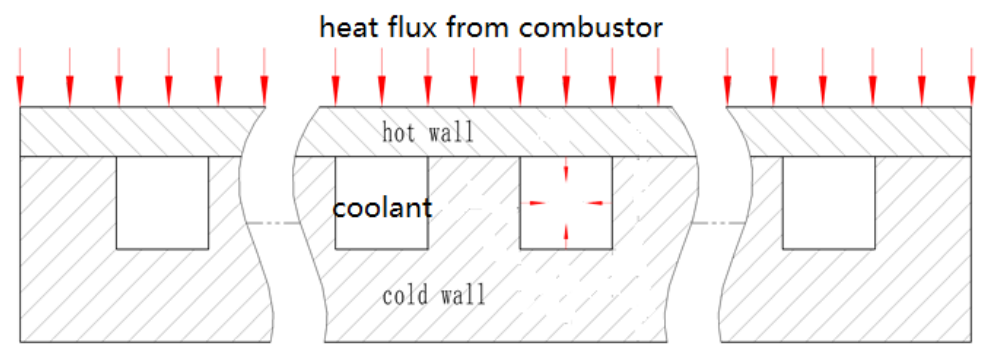

Fig. 1 Schematic drawing of the cross section of fuel-cooled wall structure in a scramjet combustor

In this study, a system which meets abovementioned demands was designed, built and tested. The one side heat flux it provided is well controlled and could be easily changed online. The tested heat flux was $0.6 \mathrm{MW} / \mathrm{m}^{2}$ with a potential of $1.0 \mathrm{MW} / \mathrm{m}^{2}$ in a near future. Various parameters such as inlet temperature, pressure and flow rate of the coolant are controllable, too. The system can serve as a benchmark test platform of regenerative cooling studies for standard experimental tests or numerical validation tests.

\section{Design of the radiative heating system}

Radiative heating method is chosen in order to realize one-side controllable heating. The temperature of radiator should be at least $2200 \mathrm{~K}$ for heat flux of $1.5 \mathrm{MW} / \mathrm{m}^{2}$ based on the Stefan-Boltzmann`s Law. Hence graphite is selected as material of the radiator for its high electric conductivity and good mechanical properties at such temperature. The ambient pressure is kept at about $10 \mathrm{~Pa}$ to protect the graphite as well as to avoid discharge in vacuum. The size of the graphite radiation plate is set to be $1300 * 50 \mathrm{~mm}$ corresponding to a typical tested cooling panel of $1000 \mathrm{~mm}$ long and $40 \mathrm{~mm}$ wide. The thickness of the cooling panel is determined by design of the embedded channels and reinforcing ribs. The graphite radiation plate and the tested cooling panel are parallel and close to each other. They are all surrounded by heat insulating structure. Figure 2 shows the arrangement of them.

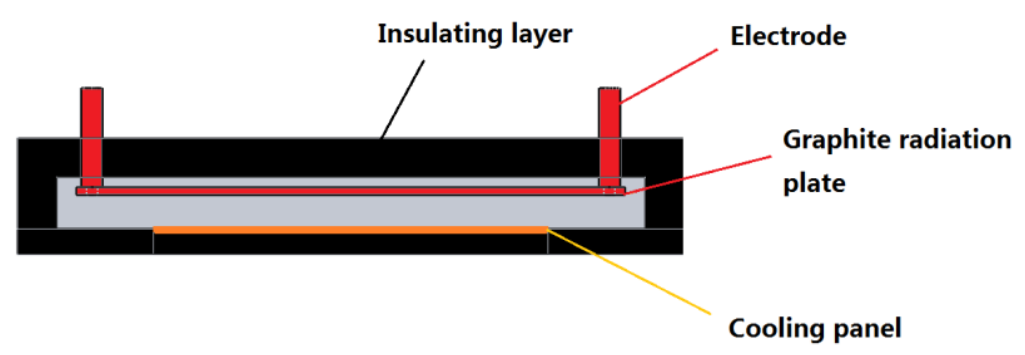

Fig. 2 Schematic drawing of the radiative heating design.

Components of the insulating structure are shown in Figure 3. There are several reflecting layers made of graphite located on the inside surface of the insulating structure. Heat loss through each reflecting layer is around $1 \%$ when thermal equilibrium reaches. Carbon felt with low thermal conductivity surrounding these layers is fixed in a stainless-steel jar, which is cooled by water. With this specially designed structure, most of the heat emitted from the graphite radiation plate is absorbed by the cooling panel at steady state. 


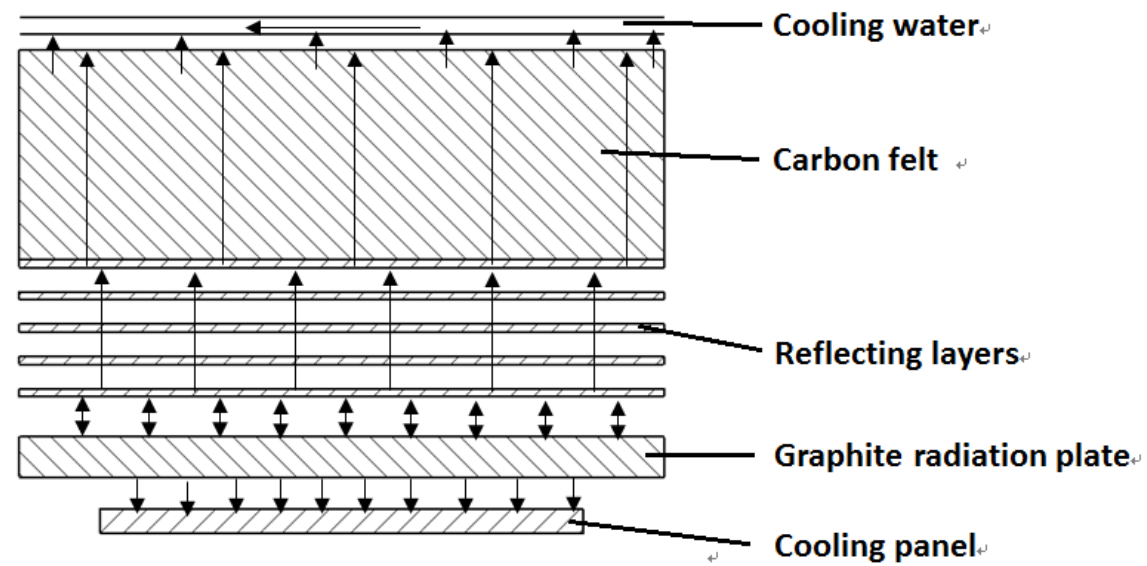

Fig. 3 Schematic drawing of the insulating structure.

The current going through the graphite radiation plate reaches 3000amps when the highest heat flux is desired. Hence contact resistance must be minimized to avoid local overheating or even failure of the whole heating system. The way to connect the graphite radiation plate and electrode is shown in Figure 4. It insures sufficient contact to decrease contact resistance and allows expansion of graphite radiation plate at high temperature.

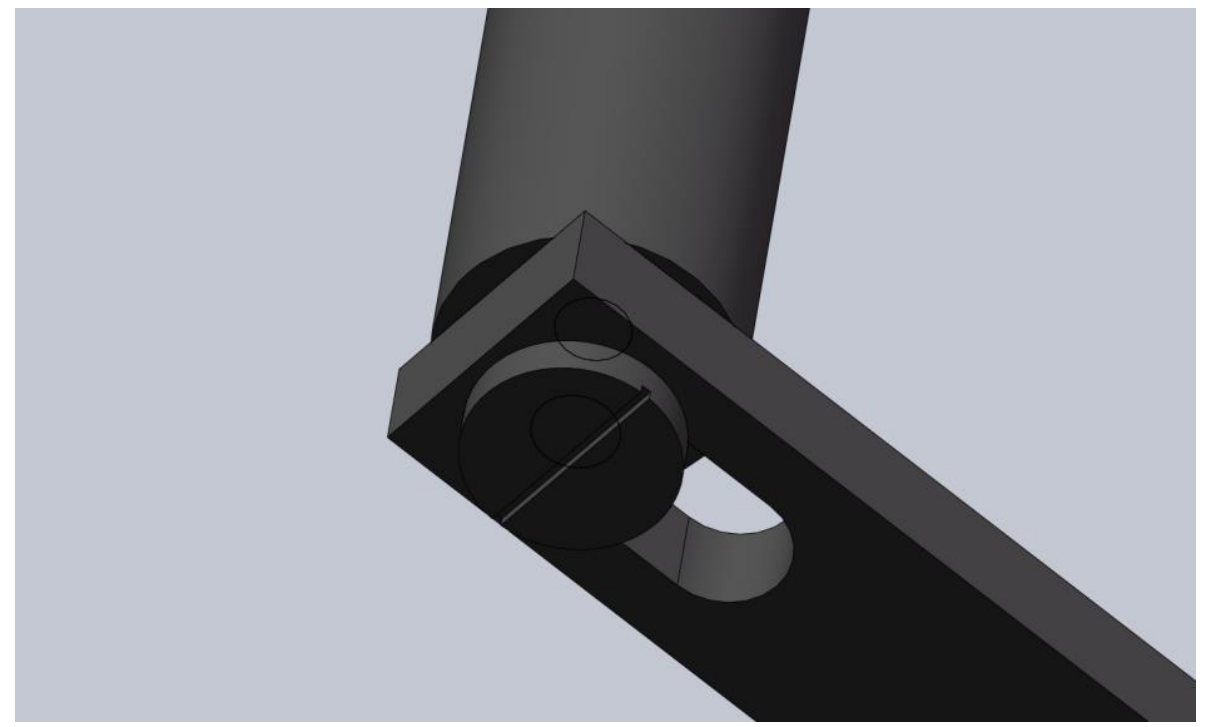

Fig. 4 The joint structure between the electrode and the graphite radiation plate.

A numerical simulation of this design described above has been performed to estimate the effective heating area with uniform heat-flux distribution. The results showed that an isothermal area of $1100 * 50 \mathrm{~mm}$ on the surface of graphite radiation plate lies above the cooling panel.

An infrared thermometer sensor of IRCON MODLINE 52-3042 is placed outside the jar through a monitoring glass window to measure the surface temperature of the graphite radiation plate. Its precision is $0.3 \%$ of reading. The temperature detected by the thermometer is converted from the heat flux emitted from the surface of the graphite radiation plate instead of its real temperature. So the heat flux can be calculated based on the StefanBoltzmann`s Law regardless of the surface emissivity. That temperature can also be used for controlling the electric power supply in PID mode.

Kerosene is provided as the coolant by a plunger pump with inlet condition of room temperature. A Coriolis mass flowmeter of SINCERITY DMF-1-3B is placed before the inlet of the cooling panel to measure the real-time mass flow rate of coolant. It sends that signal to the frequency converter to keep the mass flow rate consistent with the setting value. The mass flow rate of coolant ranges from 20 to $200 \mathrm{~g} / \mathrm{s}$ and the precision of the flowmeter is $0.1 \%$ of reading. 
A nitrogen supply system is connected to the outlet of the cooling panel to control the outlet pressure of the coolant. It can raise the pressure of coolant up to exceed the critical point under different conditions to keep undesired boiling phenomenon from happening. A sonic nozzle ${ }^{[12]}$ is placed after the outlet of the cooling panel to raise the pressure in some cases when the nitrogen supply system is absent.

There is also an optional two-stage kerosene-heating system ${ }^{[13]}$ for providing coolant of varying inlet temperatures up to $750 \mathrm{~K}$.

The heated kerosene will be cooled in an effective condenser specially designed to meet high cooling demand. The kerosene will be recycled if it doesn`t crack during heating, otherwise it will be collected alone.

Several K-type thermocouples of OMEGA are welded on the unheated surface of the cooling panel. The precision of these thermocouples is $0.75 \%$ of reading. The diameters of the welding spots are about $1 \mathrm{~mm}$. There are also two K-type thermocouples located at the inlet and outlet of the cooling panel to measure the temperatures of the coolant.

Two pressure transducers of WSTZH are placed at the inlet and outlet of the cooling panel to measure the pressures of the coolant. The precision of these pressure transducers is $0.25 \%$ of $10 \mathrm{MPa}$.

All the data are amplified and then recorded by NI PCI-6225 which also controls all the dynamic valves.

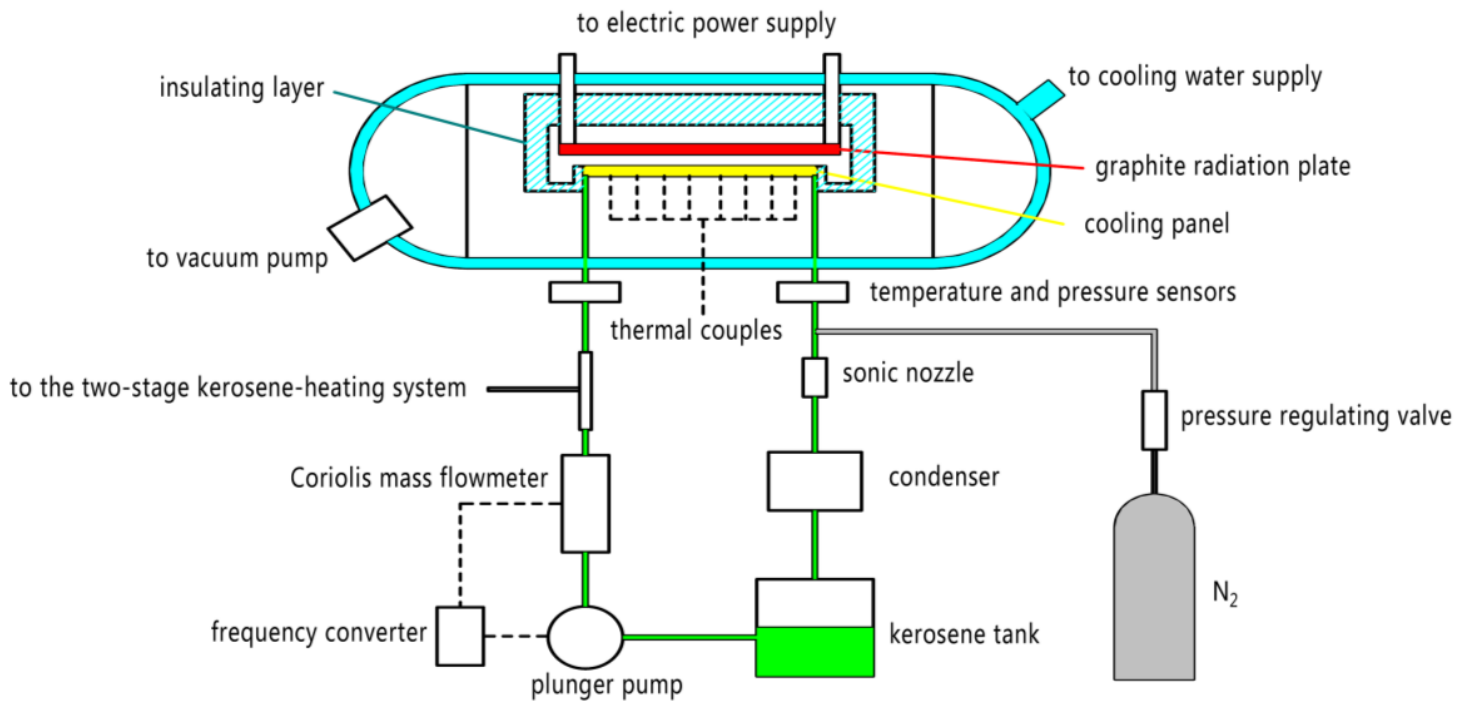

Fig. 5 Schematic drawing of the radiative heating system

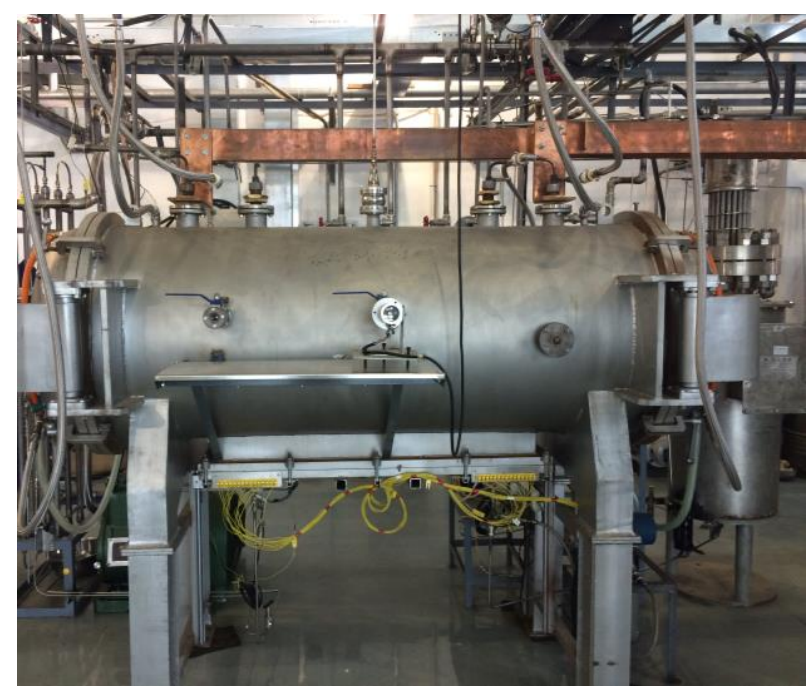

Fig. 6 Photo of the radiative heating system. 


\section{Tests and Results}

A stainless-steel cooling panel with seven micro channels embedded has been fabricated and tested in this system. Its length is $1000 \mathrm{~mm}$ and the width is $40 \mathrm{~mm}$. The height and width of each channel are both $1.5 \mathrm{~mm}$. The distance between every two adjacent channels is $3.5 \mathrm{~mm}$. The thickness of the hot wall and the cold wall is $1.2 \mathrm{~mm}$ and $1.5 \mathrm{~mm}$, respectively. Data were acquired with a sampling frequency of $20 \mathrm{~Hz}$.

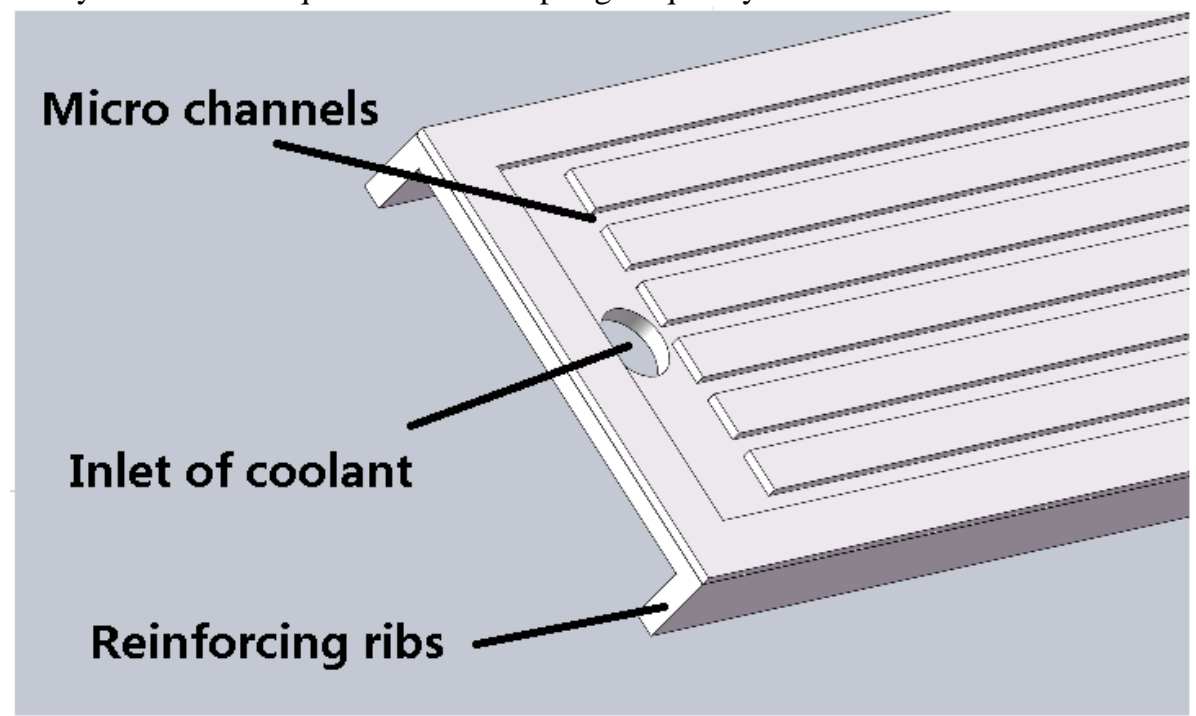

Fig. 7 Structure in a cooling panel.

The values of parameters shown in following figures are the amplified voltage from transducers. They can be converted to their real values by Table 1 .

Table 1. Instruction of items in figure 8-12

\begin{tabular}{|c|c|c|c|}
\hline Item in Figures & Corresponding Parameter & Voltage & Real Value \\
\hline T_radiator & $\begin{array}{c}\text { Temperature of the Graphite } \\
\text { radiation plate }\end{array}$ & $0-10 \mathrm{~V}$ & $1023-3273 \mathrm{~K}$ \\
\hline T_kerosene & $\begin{array}{c}\text { Outlet Temperature of } \\
\text { Kerosene }\end{array}$ & $0-10 \mathrm{~V}$ & $273-1273 \mathrm{~K}$ \\
\hline P_inlet & Inlet Pressure of Kerosene & $0-10 \mathrm{~V}$ & $0-10 \mathrm{MPa}$ \\
\hline P_outlet & Outlet Pressure of Kerosene & $0-10 \mathrm{~V}$ & $0-10 \mathrm{MPa}$ \\
\hline M_kerosene & Mass Flow Rate of Kerosene & $0-10 \mathrm{~V}$ & $0-100 \mathrm{~g} / \mathrm{s}$ \\
\hline
\end{tabular}

\section{A. Case One}

In the first test case, the nitrogen supply system was used. The inlet temperature of kerosene was $300 \mathrm{~K}$ while the outlet pressure and the mass flow rate of kerosene were set to be $3 \mathrm{MPa}$ and $90 \mathrm{~g} / \mathrm{s}$ at the beginning. After the temperature of graphite radiation plate reached $1823 \mathrm{~K}$, which corresponds to a heat flux of $0.6 \mathrm{MW} / \mathrm{m}^{2}$, four procedures were executed, which are recorded in the following figures. 


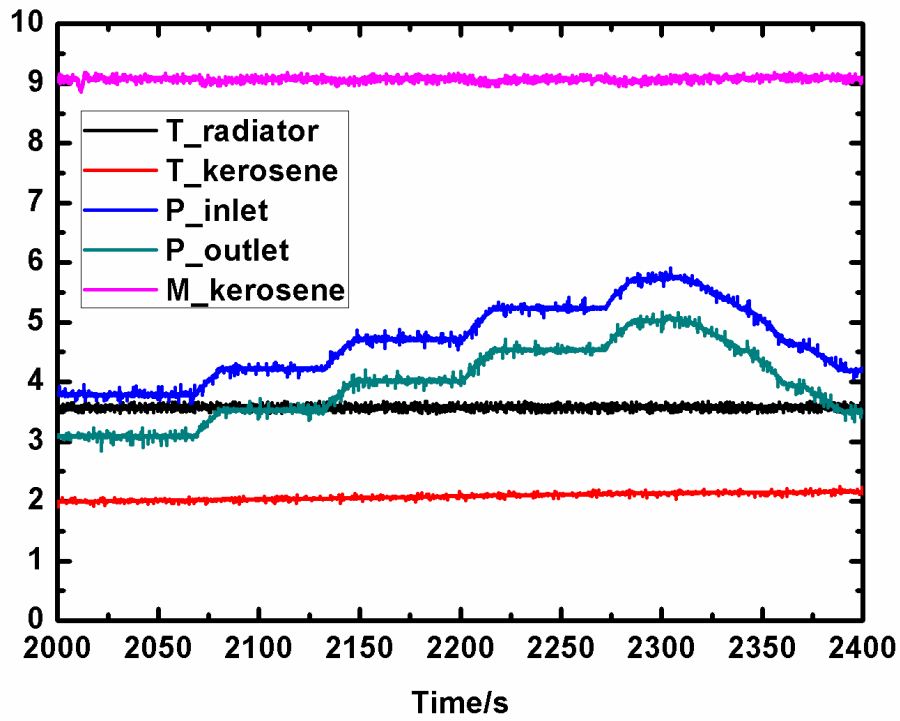

Fig. 8 Time evolution of parameters in procedure 1 of case one.

The outlet pressure varied from $3 \mathrm{MPa}$ to $5 \mathrm{MPa}$ with a step increase of $0.5 \mathrm{MPa}$. The temperature of the graphite radiation plate and the mass flow rate of kerosene were steady during the process.

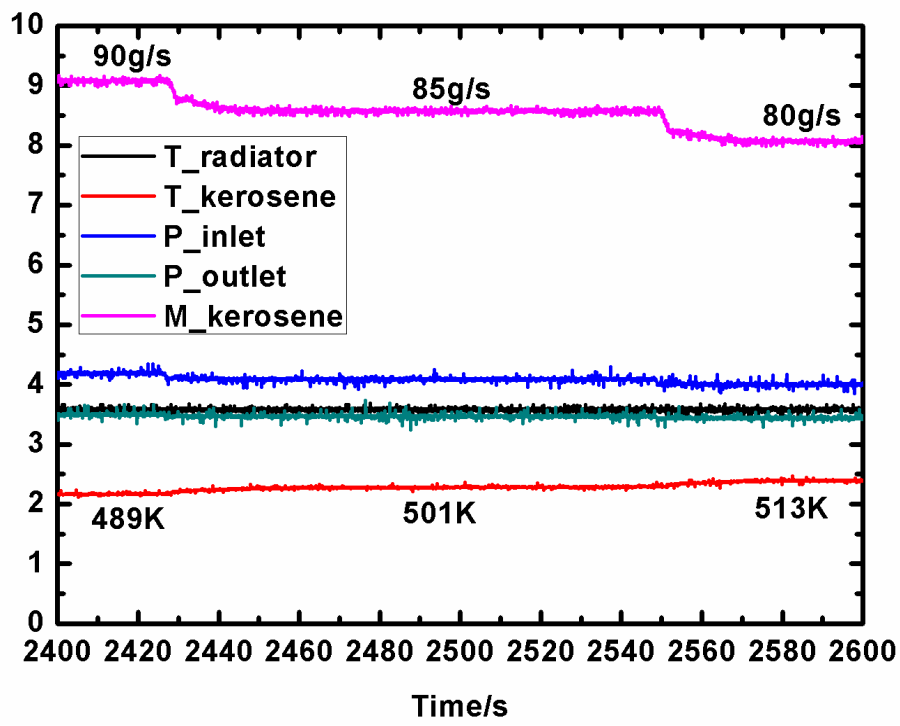

Fig. 9 Time evolution of parameters in procedure 2 of case one.

The outlet pressure was kept constant at 3.5MPa while the mass flow rate of kerosene was reduced to $85 \mathrm{~g} / \mathrm{s}$ and then to $80 \mathrm{~g} / \mathrm{s}$. The outlet temperature of kerosene increased correspondingly. 


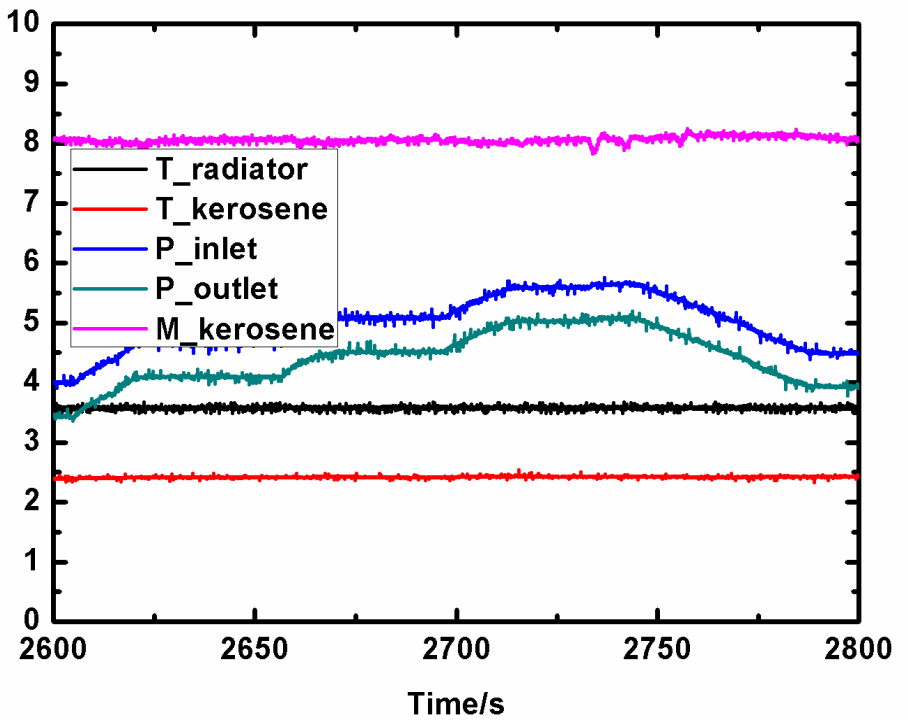

Fig. 10 Time evolution of parameters in procedure 3 of case one.

The outlet pressure varied from $3.5 \mathrm{MPa}$ to $5 \mathrm{MPa}$ with a step increase of $0.5 \mathrm{MPa}$ at a mass flow rate of $80 \mathrm{~g} / \mathrm{s}$.

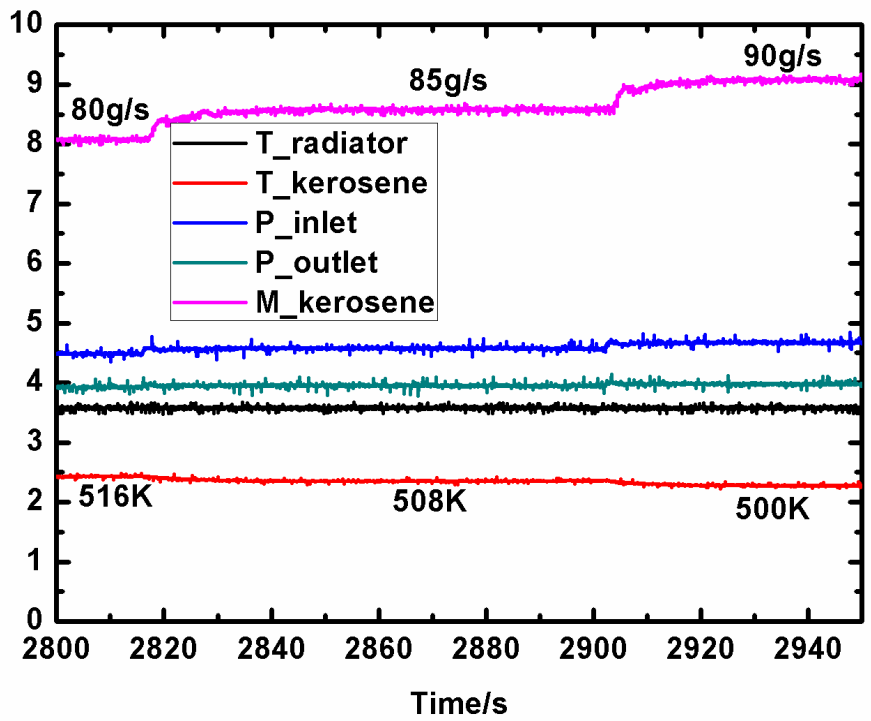

Fig. 11 Time evolution of parameters in procedure 4 of case one.

The outlet pressure remained at $4 \mathrm{MPa}$ while the mass flow rate of kerosene recovered to $90 \mathrm{~g} / \mathrm{s}$ with a corresponding decrease of the outlet temperature of kerosene.

The system showed excellent long-time performance with varying pressures and mass flow rates under a heat flux of $0.6 \mathrm{MW} / \mathrm{m}^{2}$.

\section{B. Case Two}

In the second test case, a sonic nozzle with a throat diameter of $1.5 \mathrm{~mm}$ replaced the nitrogen supply system. The mass flow rate of coolant kerosene was set to be $35 \mathrm{~g} / \mathrm{s}$ and the inlet temperature was $300 \mathrm{~K}$. The temperature of the graphite radiation plate was raised up to $1783 \mathrm{~K}$ and the temperature and pressure of kerosene increased accordingly. The outlet temperature and pressure eventually reached $670 \mathrm{~K}$ and $3 \mathrm{MPa}$, which exceeded the critical point values and maintained nearly constant for over 60 seconds. A steady state conjugated heat transfer of supercritical kerosene was realized in the system. 


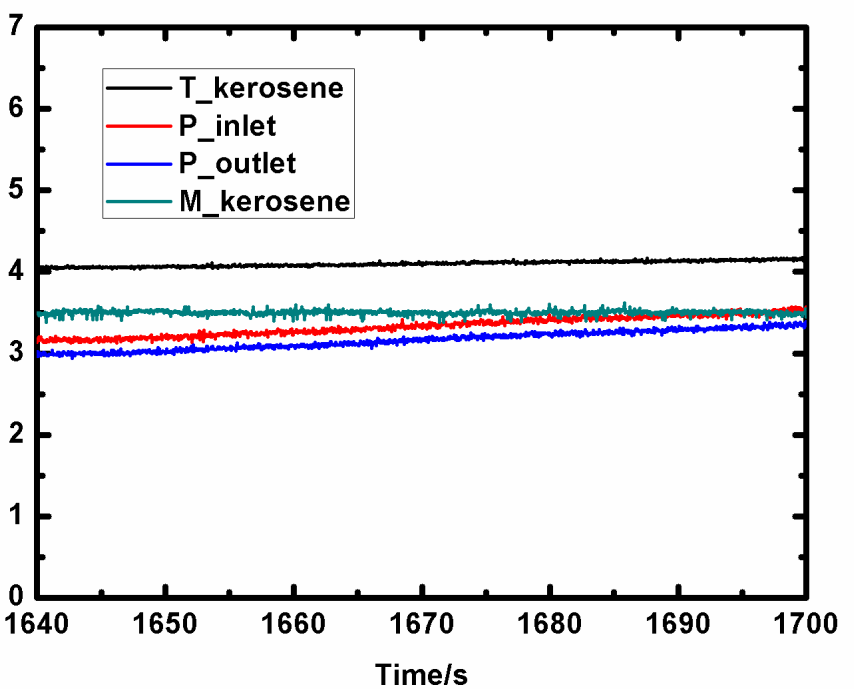

Fig. 12 Time evolution of parameters in case two.

\section{Conclusions}

This study introduced a radiative heating system suitable for experimental studies of flow and heat transfer characteristics of hydrocarbon coolant related to regenerative-cooling technique. The system has the capability of providing one-side high heat flux heating and can realize various methods for handling high temperature coolant kerosene, which were demonstrated in several tests. The system will serve a good platform for relevant studies.

\section{Acknowledgments}

This study was supported by Key Fund of LHD(NO. 2015KY03). Tao Yuan, Long Li are thanked for their exchange of ideas and experience. Ying Li, Jingquan Wang, Lingjin Meng are thanked for their technique support.

\section{References}

[1]. Wagner, W.R. and Shoji, J.M., "Advanced Regenerative Cooling Techniques for Future Space Transportation Systems," AIAA-75-1247, 1975.

[2]. Lander, H. and Nixon, A.C. Endothermic fuels for hypersonic vehicles.J. Aircraft, 8(4), 200,1971.

[3]. Ueda, Shuichi, et al. "Evaluation of Heat-flux on Scramjet Engine Wall in Mach 6 Flight Condition." 55th International Astronautical Congress. Valencia, Spain. 2006.

[4]. Fan, X.J., Zhong, F.Q., Yu, G. et al. Catalytic Cracking and Heat Sink Capacity of Aviation Kerosene Under Supercritical Conditions. Journal of Propulsion and Power, Vol. 25, No. 6, 2009, pp. 1226-1232.

[5].Zhong, F.Q., Fan, X.J., Yu, G., Li, J.G., Sung, C.J., Heat Transfer of Aviation Kerosene at Supercritical Conditions, Journal of Thermal physics and Heat Transfer,Vol. 23, No. 3, 2009, pp. 543-550.

[6]. Liu, Z.H., et al. "Convective heat transfer and pressure drop characteristics of near-critical-pressure hydrocarbon fuel in a minichannel." Applied Thermal Engineering 51.1 (2013): 1047-1054.

[7]. J. Giovanetti A, J. Spadaccini L, J. Szetela E. Deposit Formation and Heat-Transfer Characteristics of Hydrocarbon Rocket Fuels [J]. JSPACECRAFT, 1985, 22(5): 574-81.

[8]. D. L. Linne, M. L. Meyer, T. Edwards, D. A. Eitman, Evaluation of Heat Transfer and Thermal Stability of Supercritical JPe7 Fuel, NASA Technical Memo-randum 107485, AIAA-97-3041.

[9]. Zhu, K., et al. "Flow frictional resistance characteristics of kerosene RP-3 in horizontal circular tube at supercritical pressure." Experimental Thermal and Fluid Science 44 (2013): 245-252.

[10]. Li, X.F., et al. "Convective heat transfer characteristics of China RP-3 aviation kerosene at supercritical pressure." Applied Thermal Engineering 31.14 (2011): 2360-2366.

[11]. Wang, L.L., Chen, Z., Meng, H.H., Numerical study of conjugate heat transfer of cryogenic methane in rectangular engine cooling channels at supercritical pressures. Applied Thermal Engineering 54 (2013) 237-246.

[12]. Fan, X.J., et al. "Flow rate analyses and calibrations of kerosene cracking for supersonic combustion." AIAA paper 3555 (2005): 2005.

[13]. Fan, X.J., et al. "Investigation of vaporized kerosene injection and combustion in a supersonic model combustor." Journal of Propulsion and Power 22.1 (2006): 103-110. 